Nijman, J., Hendriks, M., Brabers, A., Jong, J. de, Rademakers, J. Patient activation and health literacy as predictors of health information use in a general sample of Dutch health care consumers. Journal of Health Communication: International Perspectives: 2014, 19(8), 955-969

\begin{tabular}{|l|l|}
$\begin{array}{l}\text { Postprint } \\
\text { Version }\end{array}$ & 1.0 \\
\hline Journal website & http://www.tandfonline.com/doi/abs/10.1080/10810730.2013.837561 \\
\hline Pubmed link & $\underline{\text { http://www.ncbi.nlm.nih.gov/pubmed/24397280 }}$ \\
\hline DOI & $10.1080 / 10810730.2013 .837561$ \\
\hline
\end{tabular}

This is a NIVEL certified Post Print, more info at http://www.nivel.eu

\title{
Patient Activation and Health Literacy as Predictors of Health Information Use in a General Sample of Dutch Health Care Consumers
}

\author{
JESSICA NIJMAN ${ }^{\mathrm{A}}$, MICHELLE HENDRIKS ${ }^{\mathrm{A}}$, ANNE BRABERS ${ }^{\mathrm{A}}$, JUDITH DE JONG ${ }^{\mathrm{A}}$ \& JANY \\ RADEMAKERS $^{\mathrm{A}^{*}}$ \\ A Netherlands Institute for HEALth SeRVices RESEARCH (NIVEL) , UtRECHT , THE \\ NETHERLANDS
}

\section{ABSTRACT}

In demand-led health care systems, consumers are expected to play an informed, active role in health care decisions by making use of health information. The ability to seek and use this information depends on specific knowledge, skills, and self-confidence. In this study, the authors validated a translated instrument to measure patient activation (Dutch PAM-13) in a general sample of Dutch health care consumers. Furthermore, the authors examined the relative contribution of patient activation and functional health literacy to the seeking and use of health information in The Netherlands. The mean patient activation score in the Dutch sample was higher for younger health care consumers and for those with a higher education, higher income, and better self-reported general and mental health status. More activated consumers were more likely to seek and use health information. Patient activation proved to be a stronger predictor for seeking and using health information than functional health literacy.

In the past decade, health policies in many countries, including The Netherlands, have shifted from a supply driven to a demand-led health care system. In these systems, there is a growing focus on the active role of consumers and patients (e.g., with respect to the choice of health plans, providers and treatments, self management, and participation in the patient-provider interaction. For consumers to play this role, they have to be adequately informed about relevant aspects of health and health care. Therefore, health information and its use have become significant.

Use of health information depends on four factors: The information must be available, consumers must be aware of it, consumers must have timely access to it, and consumers must comprehend it (Longo \& Patrick, 2001). Availability does not 
Nijman, J., Hendriks, M., Brabers, A., Jong, J. de, Rademakers, J. Patient activation and health literacy as predictors of health information use in a general sample of Dutch health care consumers. Journal of Health Communication: International Perspectives: 2014, 19(8), 955-969

seem a major issue; much information on health and health care is accessible on television, in written materials, or on websites (Cline \& Haynes, 2001; Damman, van den Hengel, van Loon, \& Rademakers, 2010). Some studies even warn for an “information overload” (Cline \& Haynes, 2001).

However, the mere provision of information is insufficient to enhance active and informed consumer behavior (Faber, Bosch, Wollersheim, Leatherman, \& Grol, 2009; Hibbard, Peters, Dixon, \& Tusler, 2007 ). Barriers to seeking and using health information include lack of awareness; lack of trust of data; and insufficient comprehension, understanding, and ability to assess the information, especially among people with lower socioeconomic status, minorities, and older adults (Hibbard, Slovic, Peters, Finucane, \& Tusler, 2001 ; Jewett \& Hibbard, 1996 ; Werner \& Asch, 2005 ). Elderly adults seem to use less information in general (Park, 1999 ). Tu and Hargraves (2003 ) reported that education is key to explaining differences in health information seeking. People with a college degree are twice as likely to seek health information as those without a high school diploma. Patients with a chronic condition are also more likely to seek health information (Tu \& Hargraves, 2003 ).

The ability to seek, use, and comprehend health information is further known to be related to specific individual characteristics, such as the level of patient activation and health literacy (Baker, Williams, Parker, Gazmararian, \& Nurss, 1999). The concept of patient activation has been defined as having the knowledge, skills, confidence, and behaviors needed for managing one's own health and health care (Hibbard, Stockard, Mahoney, \& Tusler, 2004 ). A 13-item instrument that measures the concept of patient activation is the Patient Activation Measure (PAM-13; Hibbard, Mahoney, Stockard, \& Tusler, 2005 ). On the basis of PAM scores, people can be assigned to one of four progressively higher levels of activation (Hibbard et al., 2005 ). Higher activated patients feel more in charge of their health and have the confidence and skills to do so. Past research has shown that higher patient activation is positively associated with various health related behaviors including lifestyle behavior, self- management, and the seeking and use of health information (Fowles et al., 2009 ; Hibbard \& Mahoney, 2010 ; Rask et al., 2009 ). As a result, a higher activated person will have a higher probability of better health outcomes (Hibbard, 2003 ; Hibbard et al., 2004 ).

A second concept relevant to the use of health information is health literacy-the ability to perform basic reading and numerical tasks required to function in a health environment (Ad Hoc Committee on Health Literacy for the Council on Scientific Affairs \& A.M.A., 1999 ). This definition refers to the functional aspects of health literacy. Broader definitions of health literacy also involve the ability to access information about health and health-related subjects, to understand it, and to apply it to one's own life (Peerson \& Saunders, 2009 ). The World Health Organization defines health literacy by including cognitive and social skills that determine the motivation and ability of individuals to gain access to, understand, and use information in ways that promote and maintain good health (Nutbeam, 1998 ). In this broader definition of health literacy aspects such as motivation, skills and selfefficacy are included (Nutbeam, 2000 ). Adequate health literacy, in this definition, is a direct prerequisite of and equivalent to adequate health information use.

There is much evidence that low functional health literacy is associated with worse health outcomes (Berkman, Sheridan, Donahue, Halpern, \& Crotty, 2011), such as 
Nijman, J., Hendriks, M., Brabers, A., Jong, J. de, Rademakers, J. Patient activation and health literacy as predictors of health information use in a general sample of Dutch health care consumers. Journal of Health Communication: International Perspectives: 2014, 19(8), 955-969

poorer knowledge about health conditions (Kalichman et al., 2000; Williams, Baker, Honig, Lee, \& Nowlan, 1998 ), lower use of preventive services (Scott, Gazmararian, Williams, \& Baker, 2002 ), higher rates of nonadherence, higher risk of hospital admission (Baker, Parker, Williams, \& Clark, 1998 ) and even higher mortality rates (Peterson et al., 2011 ). Low-literate people have more trouble comprehending and using health care information; for example, they have a poorer ability to interpret medication labels and understanding health messages (Greene, Hibbard, \& Tusler, 2005 ; Reyna, Nelson, Han, \& Dieckmann, 2009 ).

The relation between patient activation and functional health literacy has previously been studied showing a weak association and affecting different health-related outcomes (Greene et al., 2005 ; Lubetkin, Lu, \& Gold, 2010 ). This indicates the two are distinct concepts. In a study by Hibbard and colleagues (2007), numeracy, health literacy, and patient activation were compared as predictors of comprehension and use of comparative quality information. Although numeracy and literacy proved to be the strongest predictors of comprehension, making good choices that involve tradeoffs was related to patient activation. In a review study by Berkman and colleagues (2011), no firm conclusions about the relation between numeracy and health outcomes could be drawn because of few studies and inconsistent results. In our study, we chose to compare the relative contribution of patient activation and functional health literacy because both concepts have been established in the United States as predictors of seeking and use of health information. Because of inconsistent earlier results, we have decided not to include numeracy as a predictor. We also chose not to include a broader definition of health literacy because doing so might have resulted in conceptual overlap with patient activation and outcome measures (literacy being equivalent to the ability to seek and use health information). Our study has a twofold aim:

1. To validate the Dutch PAM-13 in a general sample of Dutch health care consumers

2 To examine the relative contribution of patient activation and functional health literacy to the seeking and use of health information in The Netherlands

The following are our research questions:

1 How is patient activation distributed in a general sample of Dutch health care consumers (by demographic characteristics and self-reported health status)?

2 To what extent is patient activation among Dutch health care consumers related to the seeking and use of health information?

3 Is there an association between patient activation and functional health literacy in this sample?

4 What is the relative contribution of patient activation and health literacy to the seeking and use of health information in The Netherlands?

Because previous research on patient activation and functional health literacy in relation to health information use has been done primarily in the United States, we decided to investigate the relative contribution of these two concepts on the seeking and use of health information in The Netherlands. This is the first empirical research in The Netherlands in which both concepts are studied in combination as potential predictors of health related behavior. 
Nijman, J., Hendriks, M., Brabers, A., Jong, J. de, Rademakers, J. Patient activation and health literacy as predictors of health information use in a general sample of Dutch health care consumers. Journal of Health Communication: International Perspectives: 2014, 19(8), 955-969

In this study, a new translated instrument to measure patient activation (Dutch PAM13) is validated in a general sample of Dutch health care consumers for the first time. In another study by Rademakers and colleagues, the Dutch PAM-13 instrument was psychometrically tested in a panel of chronically ill patients in The Netherlands (Rademakers, Nijman, van der Hoek, Heijmans, \& Rijken, 2012 ). Also in other countries, the PAM is mainly validated in groups of chronically ill patients (Hibbard et al., 2004 ; Hibbard et al., 2005 ; Hibbard, Mahoney, Stock, \& Tusler, 2007 ; Hibbard \& Tusler, 2007 ; Maindal, Sokolowski, \& Vedsted, 2009 ; Mosen et al., 2007 ; Remmers et al., 2009 ). Fowles and colleagues (2009) and Hibbard and Mahoney (2010) have also used the measure in a nonpatient sample.

Measures of health literacy - the Rapid Estimate of Adult Literacy in Medicine, the Newest Vital Sign, the Set of Brief Screening Questions, and the measure of Functional Communicative and Critical Health Literacy-have recently been translated in Dutch, tested on their feasibility and validated in two patient groups, one with coronary artery disease and one with diabetes type 2 (Fransen, van Schaik, Twickler, \& Essink-Bot, 2011 ). Whereas in the U.S. studies (Greene et al., 2005 Hibbard et al., 2007 ; Lubetkin, Lu, \& Gold, 2010 ), health literacy was measured with an objective instrument such as the shortened version of the Test of Functional Health Literacy, we chose the only available subjective measurement instrument because of the nature of our design (a survey with self-administered questionnaires) - the Set of Brief Screening Questions (SBSQ). The Dutch version of the questionnaire is known as SBSQ-D (Chew, Bradley, \& Boyko, 2004 ; Franssen et al., 2011). This study is also the first to use both the Dutch PAM-13 and the SBSQ-D in a general sample of health care consumers.

\section{METHOD}

\section{Participants}

The sample of the present study consisted of members of the Dutch Health Care Consumer Panel of NIVEL, The Netherlands Institute for Health Services Research. This panel consists of about 6,000 adults 18 years of age and older (Brabers, Reitsma-van Rooijen, \& de Jong, 2011 ). Migrants, however, are underrepresented in the panel. From the panel, samples can be drawn that are representative regarding gender and age for the Dutch population 18 years of age and older. Members of the panel receive a questionnaire four times a year and can quit the panel any time. Every 2 years, one third of the panel members is renewed. This renewal ensures that the panel remains a cross-section of the population; that members do not develop specific knowledge of, and attention for, health care issues; and that no questionnaire fatigue occurs. New members of the panel are sampled from the general population. Sampled people receive an information letter about the panel and are called within 1 week after receiving that letter. If they are interested, they receive first a questionnaire on background characteristics. When that questionnaire is returned, they are considered members of the panel. The protection of the collected data was registered within the Dutch Data Protection Authority (nr. 1262949). At the beginning of March 2011, a questionnaire was sent to one third $(n=2,000)$ of the panel. A written questionnaire was sent to 928 members, while 1,072 members received an invitation for an online questionnaire (according to their previously stated preference). 
Nijman, J., Hendriks, M., Brabers, A., Jong, J. de, Rademakers, J. Patient activation and health literacy as predictors of health information use in a general sample of Dutch health care consumers. Journal of Health Communication: International Perspectives: 2014, 19(8), 955-969

\section{Measures}

Among other health-related questions, the questionnaire included the following measures: the PAM 13-Dutch (Rademakers et al., 2012 ), the SBSQ-D (Fransen et al., 2011 ), and as outcome measure a set of questions assessing the seeking and use of health information (Fowles et al., 2009 ).

\section{Patient Activation Measure}

The Patient Activation Measure (PAM) is an interval-level, unidimensional, and Guttman-like measure. For this study, the translated and adapted PAM 13-Dutch was used (Rademakers et al., 2012 ). For the translation and adaptation of the PAM 13, a systematic approach conform instructions of the World Health Organization was followed. This method includes the following steps: forward translation, expert panel meeting, backward translation, pretesting/cognitive interviewing, and consensus about the final version. The procedure has been fully described in Rademakers et al. (2012).

The PAM 13-Dutch consists of 13 items assessing knowledge, skill, and confidence for managing one's own health and health care. All items have five possible responses with scores ranging from 1 (disagree strongly) to 4 (agree strongly), and one option for not applicable (N/A). Participants who filled out fewer than seven questions or answered all items with disagree strongly or agree strongly were defined as unreliable and excluded from the analysis because these participants are likely not to have responded in an accurate or truthful way (Insignia Health, 2010 ; Maindal et al., 2009 ). A sum score was calculated with items left blank scored as missing. Raw scores were transformed into standardized activation scores ranging from 0 to 100 . These activation scores were converted into one of four progressive activation levels (Insignia Health, 2010 ). The PAM has shown to be a valid and reliable instrument with good psychometric properties (Hibbard et al., 2005 ; Hibbard et al., 2004; Rademakers et al., in press). Internal consistency of the PAM in this study was good (Cronbach's $\alpha=.83$ ).

\section{Functional Health Literacy Screening Items}

In this study, a subjective measure of health literacy was included in the questionnaire. We used one of the instruments that had recently been translated in Dutch by Fransen and colleagues (2011 ). In their study, the SBSQ was the only subjective measure. It had an acceptable internal consistency (Cronbach's $\alpha=.69$ ). The SBSQ-D of functional health literacy included three questions (Fransen et al., 2011 ):

1. "How often do you have someone help you read materials?" (response options: never, occasionally, sometimes, often, always)

2. "How confident are you filling out medical forms by yourself?" (response options: extremely, quite a bit, somewhat, a little bit, not at all)

3. "How often do you have problems learning about your medical condition because of difficulty understanding written information?" (response options: never, occasionally, sometimes, often, always)

Responses were scored on a Likert scale from 1 to 4 where 1 was assigned to never or extremely and 4 to merged responses often/always and a little bit/not at all. The 
Nijman, J., Hendriks, M., Brabers, A., Jong, J. de, Rademakers, J. Patient activation and health literacy as predictors of health information use in a general sample of Dutch health care consumers. Journal of Health Communication: International Perspectives: 2014, 19(8), 955-969

value of Cronbach's alpha for the SBSQ-D in this study was .48, indicating low internal consistency. As a result, the single items were used in the analyses.

\section{Seeking and Use of Health Information}

To measure the seeking and use of health information, questions and responses were derived from the study of Fowles and colleagues (2009). Participants were asked to respond to the following statements:

1. "I find the Internet an important source of information about health and illness." (response options: strongly disagree, disagree, agree, strongly agree)

2. "I think I can recognize reliable websites about health and illness." (response options: strongly disagree, disagree, agree, strongly agree)

3. "Do you read books about health and illness?” (response options: yes, no)

4. "I know where I can find information to compare the quality of care in hospitals." (response options: strongly disagree, disagree, agree, strongly agree)

5. "I know where I can find information to compare the quality of health care plans." (response options: strongly disagree, disagree, agree, strongly agree)

6. "How much do you know about the existing differences between the various health plans?” (response options: nothing, little, enough, a lot)

Questions were scored on a 4-point Likert scale in which higher scores indicated more agreement with the statements. To determine whether a summed scale could be used, we evaluated whether these items measured a single concept by calculating internal consistency given by Cronbach's alpha. Explorative factor analysis with oblique rotation was conducted to explain as much of the variance in the set of items measuring the seeking and use of health information. Question 3 could not be included in the scale because of a factor loading lower than 0.3 (Floyd \& Widaman, $1995)$. All five remaining items formed a reliable scale $(\alpha=.71)$ ranging from 5 to 20 , in which higher scores indicated more active seeking and use of health information.

\section{Demographics}

Demographics (age, gender, education, ethnicity, income, and both self-reported general and mental health status) of the participants were already known because these characteristics were documented at the start of the panel membership and updated annually. Age was used as continuous measure and in three age groups $(<39$ years, 40-64 years, and 65 + years). Educational level was divided in three groups: low (none, primary school, vocational training), middle (secondary or vocational education) and high (professional higher education or university).

\section{Statistical Analysis}

To validate the PAM, we conducted bivariate analyses to investigate the relation between the PAM and panel member characteristics, the seeking and use of health information, and health literacy. As stated, health literacy was analyzed per item because of the low internal consistency. Pearson's correlation was used for the continuous measure of age. We used an analysis of variance to test for significant differences in means for categorical variables and a two-sample t test for binary variables. 
Nijman, J., Hendriks, M., Brabers, A., Jong, J. de, Rademakers, J. Patient activation and health literacy as predictors of health information use in a general sample of Dutch health care consumers. Journal of Health Communication: International Perspectives: 2014, 19(8), 955-969

In regression analysis, we explored the unique contributions of respectively demographics, health literacy and patient activation to the seeking and use of health information. The additional effect of patient activation on top of health literacy on the seeking and use of health information, and vice versa, was determined. Cases were excluded when demographic variables were incomplete, PAM scores were defined as unreliable, not all five items concerning the seeking and use of health information were completed, and one or more health literacy items were missing. In a multivariate linear regression analysis we added demographics (gender, age, education, ethnicity, income, general health status, mental health status), and explanatory variables health literacy (help with reading, confident filling out medical forms, problems learning about medical condition), patient activation (PAM score), or both. We reported the unadjusted R 2 and $\mathrm{R} 2$ change of each model. The change in $\mathrm{R} 2$ determined how much of the variance of the seeking and use of health information is attributed to health literacy or patient activation when controlling for demographics. For analysis, we used STATA 11.0.

\section{RESULTS}

\section{Response}

A total of 1,500 members (75.0\%) returned the questionnaire. Compared with the panel sample, nonresponse was largest in the group of men younger than 49 years. Response on the written questionnaire was somewhat higher than the online questionnaire (78.9\% and $71.6 \%$, respectively). A total of 1,432 questionnaires were used for statistical analysis; 68 participants (4.5\%) were excluded from the analysis because they answered fewer than seven items of the PAM $(n=43)$ or their responses were considered unreliable $(n=25)$. Most participants were female (54.0\%) and of Dutch origin (94.0\%). A majority (60.3\%) had completed at least secondary or vocational education. Almost $60 \%$ rated their health in general as good. Mental health was self-reported as poor or bad in $7.6 \%$ of the cases. The average age of the respondents was 55.9 years.

\section{Distribution of Patient Activation}

The overall mean patient activation score of the Dutch health care consumer panel is 56.9 (SE = 0.34). About $22 \%$ scored within the first (and lowest) activation level, $26 \%$ in Level 2, 30\% in Level 3, and 22\% in Level 4. Table 1 shows the relations between the PAM score and demographic characteristics. Participants 65 years and older have lower activation scores compared with younger age groups. Furthermore, bivariate analysis showed significantly higher PAM scores for those with a higher educational level or income, and for those with a better self-reported general or mental health status. No significant differences in activation scores were found for gender and ethnicity.

\section{[TABLE 1.]}

\section{Patient Activation and Health Information Use}


Nijman, J., Hendriks, M., Brabers, A., Jong, J. de, Rademakers, J. Patient activation and health literacy as predictors of health information use in a general sample of Dutch health care consumers. Journal of Health Communication: International Perspectives: 2014, 19(8), 955-969

There is a positive and significant relation between a higher PAM score and more active seeking and use of health information (Table 2). Participants with higher PAM scores more often agreed that internet was as source of health information.

Furthermore, higher activated participants state more often that they can recognize reliable websites and more frequently read books about health and illness. Last, the PAM was positively related to being able to find comparative information about the quality of hospitals and health plans, and knowing about the differences between health plans. Differences in the mean scores of high- and low-activated participants were most noticeable in the domain of comparative information.

\section{[TABLE 2.]}

\section{Association Between Patient Activation and Functional Health Literacy}

Two out of three items of the SBSQ-D were significantly related to patient activation (Table 3). The more confident people were with filling out medical forms, the higher their PAM score were. Those who agreed more with having problems learning about their medical condition because of difficulty understanding written information had lower PAM scores. Patient activation was not significantly related to receiving help of others with reading, but those receiving help often or always scored remarkably higher. Nevertheless, a multicomparison test showed no significant differences between groups (Bonferroni $\mathrm{p}>.05$ ).

\section{[TABLE 3. ]}

\section{Relative Contribution of Patient Activation and Health Literacy to the Seeking and Use of Health Information}

Table 4 displays the results of multivariate regression analysis by sequentially adding the block demographics, functional health literacy, and patient activation. Final regression analysis was performed on 1,257 respondents.

\section{[TABLE 4. ]}

Demographics (Model 1) explained 9\% percent of the variance ( $2=0.090)$ of the seeking and use of health information. Health literacy (Model 2) added $8 \%$ to the explained variance $(\mathrm{R} 2=0.079)$. Receiving more help of others with reading materials and being more confident with filling out medical forms were positively related to the seeking and use of health information. Problems with learning about their medical condition was negatively associated. The results of Model 3 show that patient activation added 9\% $(\mathrm{R} 2=0.091)$ to the relation compared with the first model.

In the final regression model (Model 4), we see that age, ethnicity, income, confidence with forms, problems learning, and patient activation were significant contributors to the seeking and use of health information explaining together an amount of $22.5 \%$ of the variance. A R 2 change value of 0.056 (or $5.6 \%$ ) is attributed to adding patient activation above health literacy (Model 4 - Model 2), while 0.044 (or 4.4\%) to adding health literacy above patient activation (Model 4 - Model 3). This means that although both concepts are predictors of the seeking and use of health information, patient activation explains more of the variance. 
Nijman, J., Hendriks, M., Brabers, A., Jong, J. de, Rademakers, J. Patient activation and health literacy as predictors of health information use in a general sample of Dutch health care consumers. Journal of Health Communication: International Perspectives: 2014, 19(8), 955-969

\section{DISCUSSION}

This study aimed to validate the Dutch PAM-13 in a general sample of Dutch health care consumers and to examine the relative contribution of patient activation and functional health literacy to the seeking and use of health information in The Netherlands. The overall mean patient activation score in this sample of Dutch health care consumers was 56.9, with significantly higher scores for younger people and for those with a higher educational level, higher income, and better general and mental health status. The overall mean score in our sample is remarkably lower than that reported previously in an employed population (68.6; Fowles et al., 2009) or in a sample of individuals 45 + years of age with one or more chronic diseases (61.9; Hibbard et al., 2005). Also, in comparison with the Dutch PAM validation study in a sample of chronically ill patients (Rademakers et al., in press), the mean score is relatively low (61.3). The score in the present study is most comparable with a U.S. sample of adults with chronic conditions scoring an average PAM of 56.8 (Mosen et al., 2007). For some subgroups it is established that they have lower activation scores such as for people with lower incomes, less education or poor self-reported health (Hibbard \& Cunningham, 2008 ). Because there is no overrepresentation of these subgroups in the Dutch Health Care Consumer Panel, we cannot explain the relatively low mean activation score in this sample. It is possible that the Dutch PAM-13 is more appropriate at present for use in a sample of chronically ill patients (who are already more focused on health and illness) and that rephrasing of some items and further cultural validation is needed for use in the general Dutch population. The lower overall mean activation score in The Netherlands might reflect actual differences between the Dutch and the U.S. health care system, with a greater focus on individual responsibility in the latter.

As in previous studies, age, education, income, self-reported general and mental health status were positively related to the PAM score (Hibbard et al., 2005 ; Hibbard \& Cunningham, 2008 ). Ethnicity and gender were not associated in this study, which was similar for the study with employees (Fowles et al., 2009 ) and a cohort with diabetic patients (Rask et al., 2009 ). However, given the low percentage of migrants in our sample, we are not able to draw firm conclusions with regard to ethnicity.

In this study, we found a positive and significant relation between a higher level of patient activation and more active seeking and use of health information. Differences in the mean scores of high- and low-activated participants were most noticeable in the domain of comparative information, probably because this information is more complex. Previous studies in the United States have demonstrated that activated people are more likely to seek health information, use it more often, and understand it better (Fowles et al., 2009 ; Hibbard \& Tusler, 2007 ; Peters, Dieckmann, Dixon, Hibbard, \& Mertz, 2007; Hibbard, 2009). Our results confirm that these conclusions are also valid in The Netherlands.

Unlike in some other research (Greene et al., 2005 ; Lubetkin, Lu, \& Gold, 2010) patient activation and functional health literacy were partly associated to each other. We found no significant relation between receiving help with reading and patient activation. Therefore, our findings cannot confirm the hypothesis that higher PAM scores might compensate for lower literacy skills because it better enables people to ask others for help (Hibbard et al., 2007 ). It is interesting, though, that the 
Nijman, J., Hendriks, M., Brabers, A., Jong, J. de, Rademakers, J. Patient activation and health literacy as predictors of health information use in a general sample of Dutch health care consumers. Journal of Health Communication: International Perspectives: 2014, 19(8), 955-969

participants in our study who report most help in this area also have the highest PAM scores. The trend is, however, not linear. With respect to the other health literacy domains there was an association between feeling more confident filling out medical forms and higher PAM scores. As could be expected, those participants who had problems learning about their medical condition because of difficulty understanding written information had lower activation scores.

Our study results further indicate that both patient activation and functional health literacy are related to the seeking and use of health information. However, patient activation proved to be a stronger predictor than functional health literacy. Because patient activation is a more encompassing concept, including aspects such as knowledge, skills, motivation, and confidence, this result is not surprising. A broader definition of health literacy, which goes beyond the ability to read and comprehend health information, but includes motivation, skills, and self-efficacy as Nutbeam (2000 ) suggested, would probably yield similar results. To investigate the conceptual overlap between the broader definition of health literacy and patient activation, further research is needed. To reliably measure the broader concept of health literacy, however, new instruments need to be developed (Fransen et al., 2011).

Neither patient activation nor health literacy are static concepts, and evidence exists that interventions and education can improve people's activation and literacy levels (Fowles et al., 2009 ; Terry, Fowles, Xi, \& Harvey, 2011 ). To moderate consumers to effectively make use of information in health care choices, interventions focusing on improving both patient activation and health literacy will be more successful rather those addressing health literacy alone. Therefore, more research is needed in order to develop and evaluate specific interventions focusing on individuals current level of activation and health literacy skills.

Main strength of this study is the sample that was representative of the Dutch population concerning age and gender. The fact that the study has been done in a general population outside the United States is unique. Another main strength is the design, in which the relative contribution of patient activation and functional health literacy is studied. Only few studies have studied these two predictors in combination, none of them in The Netherlands.

A limitation is that migrants are underrepresented in the panel and therefore in our study. How this affects the results is unclear, because in the present study there is no significant relation between ethnicity and the level of patient activation. If, however, the migrants that are not included in the panel generally have lower education and/or a lower income, even our relatively low mean activation score can be somewhat optimistic. The same is true for people with extremely low functional health literacy, who will also not be part of a panel that uses written questionnaires for data collection. Including them in the study might lead to a lower overall mean activation score.

Another limitation regards the subjective nature of our measures. Though the internal consistency of the PAM and the questions on health information use was reliable to good, scores might have been different when more objective measures would be used. This is even more true for our subjective measure of health literacy which had a low internal consistency. Subjective measures ask for people's interpretation of their skills, which might vary according to their personal characteristics and their point of reference, such as expectations of what normal behavior constitutes. They 
Nijman, J., Hendriks, M., Brabers, A., Jong, J. de, Rademakers, J. Patient activation and health literacy as predictors of health information use in a general sample of Dutch health care consumers. Journal of Health Communication: International Perspectives: 2014, 19(8), 955-969

further enable the possibility to give social desirable answers, thus providing a more positive picture of the actual situation.

\section{CONCLUSIONS}

The overall mean patient activation score in the Dutch sample (56.9) is remarkably lower than previously reported scores in the United States and in another validation study in The Netherlands. The PAM scores in The Netherlands were higher for younger health care consumers and for those with a higher educational level, higher income and better general and mental health status. More activated consumers were significantly more likely to seek and use health information. Differences in the mean scores of high and low activated participants were most noticeable in the domain of comparative information, probably because this information is more complex. In our study, patient activation and functional health literacy were partly associated with each other. Both patient activation and functional health literacy are related to the seeking and use of health information Patient activation, however, proved to be a stronger predictor than did functional health literacy. This means that health information use does not only depend on the level of reading skills, but also on other patient related characteristics such as feeling responsible for one's own health, motivation to look for information and self-confidence to be able to ask questions. Health communication strategies, both on an individual and on a public level, will have to address these aspects as well in order to be more effective.

\section{Acknowledgments}

The authors thank Insignia Health LLC for giving permission to translate the PAM 13 into Dutch. The copyright of the PAM 13-Dutch is held by Insignia Health (www.insigniahealth.com).

\section{REFERENCES.}

1. Ad Hoc Committee on Health Literacy for the Council on Scientific Affairs, American Medical Association. ( 1999 ). Health literacy: Report of the Council on Scientific Affairs (Rep. No. 281) . Chicago , IL : American Medical Association .

2. Baker, D. W. , Parker , R. M. , Williams , M. V. , \& Clark , W. S. ( 1998 ). Health literacy and the risk of hospital admission . Journal of General Internal Medicine , 13, $791-798$.

3. Baker , D. W. , Williams , M. V. , Parker , R. M. , Gazmararian , J. A. , \& Nurss , J. ( 1999 ). Development of a brief test to measure functional health literacy. Patient Education and Counseling, $38,33-42$.

4. Berkman , N. D. , Sheridan , S. L. , Donahue , K. E. , Halpern , D. J. , \& Crotty , K. ( 2011 ). Low health literacy and health outcomes: An updated systematic review. Annals of Internal Medicine, $155,97-107$.

5. Brabers , A. E. M. , Reitsma-van Rooijen , M. , \& de Jong , J. D. ( 2011 ). Consumentenpanel Gezondheidszorg: Basisrapport met informatie over het panel [Dutch Health Care Consumer Panel: Basis report with information on the panel] . Utrecht, The Netherlands : NIVEL .

6. Chew , L. D. , Bradley , K. A. , \& Boyko , E. J. ( 2004 ). Brief questions to identify patients with inadequate health literacy . Family Medicine , 36,588 - 594 .

7. Cline , R. J. , \& Haynes, K. M. ( 2001 ). Consumer health information seeking on the Internet: The state of the art. Health Education Research , 16, 671-692. 
Nijman, J., Hendriks, M., Brabers, A., Jong, J. de, Rademakers, J. Patient activation and health literacy as predictors of health information use in a general sample of Dutch health care consumers. Journal of Health Communication: International Perspectives: 2014, 19(8), 955-969

8. Damman , O. C. , van den Hengel , Y. K. , van Loon , A. J. , \& Rademakers , J. ( 2010 ) An international comparison of web-based reporting about health care quality: Content analysis . Journal of Medical Internet Research , 12 ( 2 ), e8

9. Faber , M. , Bosch , M. , Wollersheim , H. , Leatherman , S. , \& Grol , R. (2009). Public reporting in health care: How do consumers use quality-of-care information? A systematic review. Medical Care , 47, 1-8.

10. Floyd , F. J. , \& Widaman , K. F. ( 1995 ). Factor analysis in the development and refinement of clinical assessment instruments . Psychological Assessment , 7, 286- 299 .

11. Fowles, J. B. , Terry , P. , Xi , M. , Hibbard, J., Bloom , C. T. , \& Harvey , L. ( 2009 ). Measuring self-management of patients' and employees' health: Further validation of the Patient Activation Measure (PAM) based on its relation to employee characteristics . Patient Education and Counseling , 77, $116-122$

12. Fransen, M. P. , van Schaik, T. M. , Twickler, T. B. , \& Essink-Bot, M. L. ( 2011 ). Applicability of internationally available health literacy measures in The Netherlands . Journal of Health Communication , $16,134-149$.

13. Greene , J. , Hibbard , J. , \& Tusler , M. ( 2005 , June ). How much do health literacy and patient activation contribute to older adults' ability to manage their health? AARP Public Policy Institute Report. Retrieved from http://www.aarp.org/health/doctors-hospitals/info-062005/2005_05_literacy.html

14. Hibbard, J. $\overline{\mathrm{H}}$. ( 2003 ). Engaging health care consumers to improve the quality of care . Medical Care , $41,161-170$.

15. Hibbard, J. H. ( 2009 ). Using systematic measurement to target consumer activation strategies. Medical Care Research and Review, $66,9 S-27 S$.

16. Hibbard , J. H. , \& Cunningham , P. J. ( 2008 ). How engaged are consumers in their health and health care, and why does it matter? Research Briefs , $8,1-9$.

17. Hibbard, J. H. , \& Mahoney, E. ( 2010 ). Toward a theory of patient and consumer activation. Patient Education and Counseling , 78, $377-381$.

18. Hibbard , J. H. , Mahoney, E. R. , Stock , R. , \& Tusler , M. ( 2007 ). Do increases in patient activation result in improved self-management behaviors? Health Services Research , $42,1443-1463$.

19. Hibbard , J. H. , Mahoney, E. R. , Stockard , J. , \& Tusler , M. ( 2005 ). Development and testing of a short form of the patient activation measure . Health Services Research , 40 , $1918-1930$.

20. Hibbard, J. H. , Peters , E. , Dixon , A. , \& Tusler , M. ( 2007 ). Consumer competencies and the use of comparative quality information: It isn't just about literacy. Medical Care Research and Review , 64, 379-394 .

21. Hibbard , J. H. , Slovic , P. , Peters , E. , Finucane , M. L. , \& Tusler , M. ( 2001 ). Is the informed-choice policy approach appropriate for Medicare beneficiaries? Health Affairs , 20 , $199-203$.

22. Hibbard , J. H. , Stockard , J. , Mahoney , E. R. , \& Tusler , M. ( 2004 ). Development of the Patient Activation Measure (PAM): Conceptualizing and measuring activation in patients and consumers . Health Services Research , 39, $1005-1026$.

23. Hibbard , J. H. , \& Tusler, M. ( 2007 ). Assessing activation stage and employing a "next steps" approach to supporting patient self-management . Journal of Ambulatory Care Management , $30,2-8$.

24. Insignia Health, LLC. ( 2010 ). Patient Activation Measure (PAM) 13 license materials . Portland, OR : Author .

25. Jewett , J. J. , \& Hibbard , J. H. ( 1996 ). Comprehension of quality care indicators: Differences among privately insured, publicly insured, and uninsured . Health Care Financing Review , 18, $75-94$.

26. Kalichman, S. C. , Benotsch , E. , Suarez , T. , Catz , S. , Miller , J. , \& Rompa , D. ( 2000 ). Health literacy and health-related knowledge among persons living with HIVIAIDS . American Journal of Preventive Medicine , $18,325-331$.

27. Longo, D. R. , \& Patrick , T. B. ( 2001 ). Consumer reports and health care information: A call for research . Journal of Health Care Finance , 28, $92-96$.

28. Lubetkin , E. I. , Lu , W. , \& Gold , M. R. ( 2010 ). Levels and correlates of patient activation in health center settings: Building strategies for improving health outcomes . Journal of Health Care for the Poor and Underserved , 21, 796-808. 
Nijman, J., Hendriks, M., Brabers, A., Jong, J. de, Rademakers, J. Patient activation and health literacy as predictors of health information use in a general sample of Dutch health care consumers. Journal of Health Communication: International Perspectives: 2014, 19(8), 955-969

29. Maindal , H. T. , Sokolowski , I. , \& Vedsted , P. (2009). Translation, adaptation and validation of the American short form Patient Activation Measure (PAM13) in a Danish version. BMC Public Health , 9, 209.

30. Mosen , D. M. , Schmittdiel , J. , Hibbard , J. , Sobel , D. , Remmers , C. , \& Bellows , J. ( 2007 ). Is patient activation associated with outcomes of care for adults with chronic conditions? Journal of Ambulatory Care Management , 30, $21-29$.

31. Nutbeam , D. ( 1998 ). Health promotion glossary . Health Promotion International , 13 , $349-364$.

32. Nutbeam , D. ( 2000 ). Health literacy as a public health goal: A challenge for contemporary health education and communication strategies into the 21st century . Health Promotion International , 15, 259-267.

33. Park, D. C. ( 1999 ). Aging and the controlled and automatic processing of medical information and medical intentions. Mahwah, $\mathrm{NJ}$ : Erlbaum .

34. Peerson , A. , \& Saunders , M. ( 2009 ). Health literacy revisited: What do we mean and why does it matter? Health Promotion International , 24, 285 - 296.

35. Peters , E. , Dieckmann , N. , Dixon , A. , Hibbard , J. H. , \& Mertz , C. K. ( 2007 ). Less is more in presenting quality information to consumers. Medical Care Research and Review, 64, $169-190$.

36. Peterson, P. N. , Shetterly , S. M. , Clarke , C. L., Bekelman , D. B., Chan , P. S. , Allen , L. A. ... Masoudi , F. A. ( 2011 ). Health literacy and outcomes among patients with heart failure . JAMA , 305, $1695-1701$.

37. Rademakers , J. , Nijman , J. L. , van der Hoek , L. , Heijmans , M. , \& Rijken , M. ( 2012 ). Measuring patient activation in The Netherlands: Translation and validation of the American short form Patient Activation Measure (PAM13). BMC Public Health , $12,577$. doi: 10.1186/1471-2458-12-577

38. Rask , K. J. , Ziemer , D. C. , Kohler , S. A. , Hawley, J. N. , Arinde , F. J. , \& Barnes , C. S. ( 2009 ). Patient activation is associated with healthy behaviors and ease in managing diabetes in an indigent population. Diabetes Educator , 35, 622 - 630 .

39. Remmers , C. , Hibbard , J. , Mosen , D. M. , Wagenfield, M. , Hoye , R. E. , \& Jones , C. ( 2009 ). Is patient activation associated with future health outcomes and healthcare utilization among patients with diabetes? Journal of Ambulatory Care Management , 32 , $320-327$.

40. Reyna , V. F. , Nelson , W. L. , Han , P. K. , \& Dieckmann , N. F. ( 2009 ). How numeracy influences risk comprehension and medical decision making. Psychological Bulletin , 135, $943-973$.

41. Scott , T. L. , Gazmararian , J. A. , Williams , M. V. , \& Baker , D. W. ( 2002 ). Health literacy and preventive health care use among Medicare enrollees in a managed care organization. Medical Care , 40, 395-404.

42. Terry , P. E. , Fowles, J. B. , Xi , M. , \& Harvey , L. ( 2011 ). The ACTIVATE study: Results from a group-randomized controlled trial comparing a traditional worksite health promotion program with an activated consumer program . American Journal of Health Promotion , 26, e64-e73.

43. Tu , H. T. , \& Hargraves , J. L. ( 2003 , March ). Seeking health care information: Most consumers still on the sidelines. Issue Brief No. 61. Center for Studying Health System Change. Retrieved from http://www.hschange.org/CONTENT/537/?words=Tu\%20\&\%20Hargraves\%202003

44. Werner, R. M. , \& Asch, D. A. ( 2005 ). The unintended consequences of publicly reporting quality information. JAMA , 293, $1239-1244$.

45. Williams, M. V. , Baker , D. W. , Honig , E. G. , Lee, T. M. , \& Nowlan , A. ( 1998 ). Inadequate literacy is a barrier to asthma knowledge and self-care . Chest , 114, $1008-$ 1015 . 
Nijman, J., Hendriks, M., Brabers, A., Jong, J. de, Rademakers, J. Patient activation and health literacy as predictors of health information use in a general sample of Dutch health care consumers. Journal of Health Communication: International Perspectives: 2014, 19(8), 955-969

\section{TABLES}

Table 1. Demographic characteristics and health status of members of the Dutch Health Care Consumer Panel, by mean PAM score

\begin{tabular}{lrrcc}
\hline & $n$ & $\%$ & PAM score $(M)$ & $p$ \\
\hline Age group (years) & 1,432 & & & $<.001$ \\
18-39 & 321 & 22.4 & 57.73 & \\
40-64 & 601 & 42.0 & 58.09 & $n s$ \\
>65 & 510 & 35.6 & 54.90 & \\
Gender & 1,428 & & & \\
Male & 659 & 46.0 & 56.51 & \\
Female & 773 & 54.0 & 57.18 & \\
Education & 1,394 & & & \\
Low & 223 & 16.0 & 53.91 & \\
Middle & 841 & 60.3 & 56.55 & \\
High & 330 & 23.7 & 60.17 & \\
Ethnicity & 1,428 & & & \\
Dutch & 1343 & 94.0 & 56.83 & \\
Other & 85 & 6.0 & 57.76 & \\
Income (euros) & 1,359 & & & \\
<1350 & 210 & 15.5 & 55.65 & \\
1350-1750 & 200 & 14.7 & 54.01 & \\
1750-2100 & 211 & 15.5 & 57.66 & \\
2100-2500 & 217 & 16.0 & 56.26 & \\
2500-3100 & 255 & 18.8 & 56.93 & \\
>3500 & 266 & 19.6 & 59.91 & \\
General health status & 1,422 & & & \\
Poor/bad & 236 & 16.6 & 52.14 & \\
Good & 848 & 59.6 & 55.98 & \\
Very good & 262 & 18.4 & 60.84 & \\
Excellent & 76 & 5.3 & 67.81 & \\
Mental health status & 1,417 & & & \\
Poor/bad & 108 & 7.6 & 52.79 & \\
Good & 673 & 47.5 & 54.43 & \\
Very good & 400 & 28.2 & 59.28 & \\
Excellent & 236 & 16.7 & 61.72 & \\
\hline
\end{tabular}

Note. $\mathrm{PAM}=$ Patient Activation Measure. 
Nijman, J., Hendriks, M., Brabers, A., Jong, J. de, Rademakers, J. Patient activation and health literacy as predictors of health information use in a general sample of Dutch health care consumers. Journal of Health Communication: International Perspectives: 2014, 19(8), 955-969

Table 2. Seeking and use of health information, by mean PAM score

\begin{tabular}{|c|c|c|c|c|}
\hline & $n$ & $\%$ & PAM score $(M)$ & $p$ \\
\hline $\begin{array}{l}\text { Internet important source of health } \\
\text { information }\end{array}$ & 1,393 & & & $<.001$ \\
\hline Disagree strongly & 100 & 7.2 & 54.59 & \\
\hline Disagree & 282 & 20.2 & 54.69 & \\
\hline Agree & 778 & 55.9 & 56.63 & \\
\hline Agree strongly & 233 & 16.7 & 61.59 & \\
\hline Recognize reliable websites & 1,396 & & & $<.001$ \\
\hline Disagree strongly & 126 & 9.0 & 52.15 & \\
\hline Disagree & 627 & 44.7 & 53.99 & \\
\hline Agree & 588 & 42.3 & 59.99 & \\
\hline Agree strongly & 55 & 4.0 & 66.80 & \\
\hline Read books about health and illness & 1,421 & & & $<.001$ \\
\hline Yes & 568 & 40.0 & 58.96 & \\
\hline No & 853 & 60.0 & 55.52 & \\
\hline $\begin{array}{l}\text { Find comparative information about } \\
\text { quality of hospitals }\end{array}$ & 1,410 & & & $<.001$ \\
\hline Disagree strongly & 101 & 7.2 & 54.18 & \\
\hline Disagree & 677 & 48.0 & 54.43 & \\
\hline Agree & 593 & 42.1 & 59.20 & \\
\hline Agree strongly & 39 & 2.8 & 70.54 & \\
\hline $\begin{array}{l}\text { Find comparative information about } \\
\text { quality of health plans }\end{array}$ & 1,413 & & & $<.001$ \\
\hline Disagree strongly & 72 & 5.1 & 53.32 & \\
\hline Disagree & 539 & 38.2 & 53.69 & \\
\hline Agree & 754 & 53.4 & 58.70 & \\
\hline Agree strongly & 48 & 3.4 & 69.56 & \\
\hline $\begin{array}{l}\text { Know about differences between } \\
\text { various health plans }\end{array}$ & 1,423 & & & $<.001$ \\
\hline Nothing & 146 & 10.3 & 52.25 & \\
\hline Little & 713 & 50.1 & 54.95 & \\
\hline Enough & 550 & 38.6 & 60.26 & \\
\hline A lot & 14 & 1.0 & 72.84 & \\
\hline
\end{tabular}

Note. $\mathrm{PAM}=$ Patient Activation Measure. 
Nijman, J., Hendriks, M., Brabers, A., Jong, J. de, Rademakers, J. Patient activation and health literacy as predictors of health information use in a general sample of Dutch health care consumers. Journal of Health Communication: International Perspectives: 2014, 19(8), 955-969

Table 3. Functional health literacy level, by mean PAM score

\begin{tabular}{lrrrc}
\hline & $n$ & & PAM & \\
& \multicolumn{1}{c}{$n$} & score $(M)$ & $p$ \\
\hline Help with reading & 1,429 & & & $n s$ \\
Never & 1064 & 74.5 & 56.93 & \\
Occasionally & 232 & 16.2 & 56.34 & \\
Sometimes & 98 & 6.9 & 56.19 & \\
Often/always & 35 & 2.5 & 60.56 & \\
Confident filling out medical forms & 1,422 & & & $<.001$ \\
$\quad$ Not at all/a little bit & 82 & 5.8 & 49.58 & \\
Somewhat & 169 & 11.9 & 50.28 & \\
Quite a bit & 843 & 59.3 & 56.71 & \\
Extremely & 328 & 23.1 & 62.34 & \\
Problems learning about medical condition & 1,426 & & & $<.001$ \\
$\quad$ Never & 669 & 46.9 & 59.83 & \\
Occasionally & 425 & 29.8 & 55.00 & \\
Sometimes & 297 & 20.8 & 53.15 & \\
Often/always & 35 & 2.5 & 52.56 & \\
\hline
\end{tabular}

Note. $\mathrm{PAM}=$ Patient Activation Measure.

Table 4. Multivariate regression models predicting the seeking and use of health information $(N=1,257)$

\begin{tabular}{lcccc}
\hline & Model 1 & Model 2 & Model 3 & Model 4 \\
\hline Constant & $10.80^{* *}$ & $10.30^{* *}$ & $8.53^{* *}$ & $8.74^{* *}$ \\
Gender & .23 & .08 & .20 & .08 \\
Age & $-.02^{* *}$ & $-.02^{* *}$ & $-.02^{* *}$ & $-.02^{* *}$ \\
Education & $.42^{* *}$ & .16 & $.28^{*}$ & .11 \\
Ethnicity & $.68^{*}$ & $.67^{*}$ & $.63^{*}$ & $.63^{*}$ \\
Income & $.12^{*}$ & $.09^{*}$ & $.12^{*}$ & $.09^{*}$ \\
General health status & $.20^{*}$ & .10 & .00 & -.04 \\
Mental health status & .07 & -.01 & -.03 & -.07 \\
Help with reading & - & $.24^{*}$ & - & .16 \\
Confident filling out medical forms & - & $.72^{* *}$ & - & $.53^{* *}$ \\
Problems learning about medical & - & $-.40^{* *}$ & - & $-.34^{* *}$ \\
$\quad$ condition & & & & $.05^{* *}$ \\
Patient activation score & - & - & $.06^{* *}$ & $.169^{* *}$ \\
$R^{2}$ & $.090^{* *}$ & $.181^{* *}$ & $.225^{* *}$ \\
Change in $R^{2}$ & & .079 & .091 & .135 \\
\hline
\end{tabular}

Note. Model 1: gender, age, education, ethnicity, income, general and mental health status (demographics); Model 2: Model 1+health literacy (SBSQ); Model 3: Model 1+patient activation (PAM score); Model 4: Model $1+$ patient activation (PAM score) + health literacy (SBSQ). Dash indicates not applicable.

${ }^{*} p<.05 .{ }^{* *} p<.001$. 